\title{
Home Intervention For Mother And Premature Infant: A Literature Review
}

\author{
${ }^{13}$ Rinik Eko Kapti, ${ }^{2}$ Moses Glorino Rumambo Pandin \\ ${ }^{1}$,Student At Faculty Of Nursing Sciences, Universitas Airlangga \\ ${ }^{2}$ Lecturer At Faculty Of Cultural Sciences, Universitas Airlangga \\ ${ }^{3}$ Lecturer At Faculty Of Medicine, Universitas Brawijaya \\ Email: rinik.eko.kapti-2020@fkp.unair.ac.id
}

\begin{abstract}
Background: Premature babies have a greater risk for having health issues after being discharged from the hospital whilst the mother ability to provide premature baby care still has many issues as well. Interventions are needed to be given to mothers at home to improve the ability of mothers to care their premature babies. Methods: Search for articles used the bolean operator of "or" and "and" with the keywords used were "preterm or premature", "intervention or program", and "mother and home". Data based used were Sciencedirect, Ebscohost, PubMed, SAGE, Proquest and Scopus with inclusion criteria using full text in English from 2018 to 2021 . There were 428 articles obtained, the articles were then screened by reading the main focus of articles with paying attention to the topic and the suitability of article content and we obtained 13 suitable articles.

Results: The interventions at home carried out for mothers and premature babies were divided into two namely the follow-up interventions from the hospital and the interventions carried out at the patient's home. Seven articles about research of interventions that were as a combination from hospital intervention with follow-up hospital intervention plus five full interventions at the patient's home. Interventions were provided through home visits ( 12 articles) and by telephone ( 1 article). The results of the article analysis resulted in 4 main themes of intervention for mothers and premature babies, they were health education, counceling, support, and care for premature babies.

Conclusion: Quality care is essential for the best health, growth and development of premature babies. Interventions need to be carried out by health workers to ensure the readiness and ability of mothers to care for their babies. Maternal readiness and abilities can be improved by providing health education, counseling, support and care for premature babies.

Key words: intervention, premature, house

Corresponding Author :

Rinik Eko Kapti, Nursing Science Faculty, Airlangga University, Surabaya, East Java, Indonesia; e-mail: rinik.eko.kapti-2020@fkp.unair.ac.id
\end{abstract}




\section{BACKGROUND}

Fifteen million babies are born prematurely each year, which means that more than 1 in 10 births are premature. Globally, prematurity is the leading cause of death in children under 5 years of age, with approximately 1 million children dying each year due to complications of preterm birth. Based on data, it shows that there is an increase in preterm births every year (1). Preterm birth is birth before 37 weeks of gestation and included as small for gestational age, which is the cause of low birth weight (LBW), which is also an indirect cause of neonatal mortality. LBW contributes to $60 \%$ to $80 \%$ of all neonatal deaths. The global prevalence of LBW is $15.5 \%$, which amounts to about 20 million LBW babies born every year, $96.5 \%$ of them in developing countries (2).

Premature babies have a higher risk of experiencing health issues after discharge from hospital, in the first year life of premature babies have a $25-50 \%$ risk compared to normal babies 8-10\% for experiencing health issues (3). Premature infants are at increased risk of rehospitalization due to feeding difficulties and jaundice (4). The rehospitalization rate in premature infants which is $7.4 \%$ caused by preventable factors such as milk aspiration, diarrhea and infection (5). This condition demands the readiness of parents or caregivers to care for premature babies at home

Currently, the ability of mothers to provide care for premature babies still has many problems. This condition is caused because mothers experience problems of anxiety, helplessness, frustration and guilt. Mothers also feel unskilled and confident to care for their premature babies $(6,7)$. Mother's mental health with preterm birth is one of the important factors in achieving infant health and family stability (8). In addition, mothers feel that their knowledge regarding the care of premature babies is still lacking, so they try to find and increase their knowledge in order to provide care for their babies (9).

Increasing the ability of mothers to care for premature babies would improve the care for their babies. Proper treatment will reduce morbidity and mortality in premature babies (2). Interventions are needed to be given to mothers at home when caring them. This intervention will help mothers to go through the process of changing the role of a woman to become a mother, increasing the ability and confidence of mothers in caring for their babies, which in turn would affect the mental health of the mother and also affect the health, growth and development of premature babies as well. This literature review aims to provide an overview of what interventions could be provided by health workers for mothers with premature babies at home.

\section{METHOD}

This literature review used the source of research articles using experimental design. The article should describe the variables corresponding to the problem discussed. Search for articles using the operator of "or" and "and". Data collection was carried out in March 2021 with the keywords [preterm or premature] and [intervention or program] and mother and home. Data based used were Sciencedirect, Ebscohost, PubMed, SAGE, Proquest and Scopus with inclusion criteria using full text with English language in the period 2018 to 2021.

We obtained 428 articles which were 8 from Scienceirect, 269 from Ebscohost, 150 from PubMed, 250 from SAGE, 305 from Proquest, and 42 from Scopus. The articles then screened by reading the main article part with focusing on the topic and the suitability of the article content from the abstract, keywords, introduction, and conclusion. In the end, there were 13 articles that matched the predetermined criteria and were used in this literature review. 


\section{RESULT AND DISCUSSION}

Thirteen articles had been obtained for the research results with the designs used were randomized controlled trial, clinical trial and quasi experimental. The results of the analysis showed that the intervention carried out for mothers and premature babies at home can be divided into 2, they are follow-up intervention in the hospital and intervention fully carried out in the patient's home. Seven articles examined that interventions were a combination of hospital interventions and follow-up hospital interventions whilst other five articles conducted full-time interventions at the patient's home. Interventions were provided through home visits (12 articles) and by telephone ( 1 article). The article further analyzed critically and produced four main themes of intervention for mothers and premature babies at home which were health education, counseling, support and care for premature babies.

\section{Health Education}

The purpose of providing health education is to help individuals getting information about health problems and making them to have rational decisions about the care of premature babies. Acquiring knowledge and understanding is crucial for providing them education with the main aims are to make mothers more aware of the health of their premature babies and to make it easier for mothers to choose care in the healthiest way so that they are able to maintain the health of both mothers and their premature babies (10).

In order to reduce neonatal morbidity and mortality due to premature birth, there is an important need to increase the knowledge and skills not only for mothers but also other caregivers at home such as grandmothers. Based on the results of the study, there is a need to improve counseling and health education for newborns and special care for premature babies at home (11).

We found six articles that examined health education in mothers with premature babies. The health education provided was a follow-up session from previous sessions that had been carried out at the hospital as a form of reinforcement or booster from previous interventions at the hospital and then interventions that were overall carried out at home. Health education was provided through home visits, web based, and phone call at home.

The health education given to mothers with premature babies is about knowledge and skill about the concept of prematurity, skin to skin contact with kangaroo mother care, breastfeeding premature babies, exclusive breastfeeding, management of premature babies after discharged from hospital, effective parenting strategies, and about parental coping. It also provided knowledge related to premature babies about how to recognize baby stress signs, facial expressions, quality of motor behavior, posture and muscle tone, how to provide stimulation, how to prevent babies from excessive stimulation, touch, movement, massage and multi sensory stimulation (12-16).

The health education provided had an influence on mothers and premature babies where the results showed higher exclusive breastfeeding behavior and a lower proportion of mothers who did not breastfeed (14). The confidence to care premature babies showed significantly higher in mothers who received complete and special health education $(13,17)$. Meanwhile, the effect of education given to mothers on premature babies was that premature babies had higher cognitive and motoric abilities (18). 


\section{Counseling}

Counseling aims to empower people to make healthy choices. Education and knowledge alone do not motivate decision making. Counseling is basically a process that facilitates and assists individuals to move forward (10). In the situation of mothers with premature babies, mothers have an issue to have normal relationships with their babies and there is also a fear of caring them. Counseling with mothers on this condition could help improve the condition and improve the health of both mother and baby (19).

We found three articles that examined counseling on mothers with premature babies. Counseling was conducted through home visits or video consultations. The consultation that was carried out covering the mother's experience related to the care of premature babies, including skin to skin contact and breastfeeding. During the consultation, mothers discussed the care what their premature baby needs, problems or obstacles in the care of premature babies and how to solve these problems or obstacles $(13,20,21)$.

In addition to health workers, counseling to mothers of premature babies could also be conducted using the peer counseling method. Peers counselors were the mother having had premature babies aging between 1 and 3 years and had positive experiences on breastfeeding them. Before peer counselors conducted counseling, they would be given training with the aim to prepare these mothers to become counselors (13).

The counseling given had an influence on mothers as well as on premature babies where the results showed that the intervention group produced fewer problems, mothers had relatively lower levels of depression and anxiety risk. The behavior of mothers in the care of premature babies which was exclusive breastfeeding showing better and the behavior of seeking appropriate health services for premature babies when problems arise were also better $(13,21)$.

\section{Support}

Support can be defined as feeling supported or feeling available or feeling accepted. Support can be instrumental, informational, or emotional. Instrumental support is defined as the provision of materials or assistance. Information support refers to providing advice, guidance, or providing information that can help someone solve problems and emotional support involves expressions of sympathy, caring, self-respect, value or encouragement (22). Emotional supports provided to mothers of premature babies are divided into two namely formal support provided by health workers and informal support provided by husbands or partners and mothers who have premature babies (24).

We found three articles examining support for mothers with preterm infants. The form of support that could be given to mothers is a support from family and support from health workers. Family support could be both instrumental and emotional. Family support could be done by carrying out care for premature babies i.e skin to skin contact as known as Kangooro Mother Care (KMC) by involving husband or grandmother. KMC requires the involvement of the husband or family to support in the form of replacing the mother to do KMC when the mother getting tired or taking a shower or providing the needs when the mother doing $\mathrm{KMC}$, for example helping to prepare food for the mother (21).

Support from health workers to mothers with premature babies by providing them the information and emotional support. Health worker support can be provided through support during the transition from hospital to home care. In this study, nurses provided a supportive intervention by being present at the premature baby care center before the baby was planned to go home to 
check the readiness of the mother, the baby's health status and the transitional condition. The nurse drived the parents and baby to their home. During the trip to the house, the nurse provided information to the parents and the nurse accompanied the mother so that she could adapt to new situations and starts caring for her baby at home for a few hours (23).

Emotional support could reduce and prevent maternal stress while carrying out her new role and caring for premature babies (25). Emotional support helps mothers to overcome difficulties in caring for premature babies, by encouraging mothers to ask questions about the care for their premature babies and to describe the difficulties they have had while caring for their premature babies. Mothers can also be given the opportunity to ask questions related to problems with the care of premature babies (13)

\section{Premature Baby Care}

Treatment of premature babies was carried out during home visits by health workers. Treatment of premature babies was followed by examinating health conditions, growth and development of the premature baby. Adequate care for premature babies will prevent unwanted health conditions. Conditions that are often experienced by premature babies are respiratory problems, hypothermia, hypoglycemia and hyperbilirubinemia (4).

Care for premature babies includes feeding, thermoregulation and infection prevention. Feeding premature babies is the most important skill, so parents should learn it well, because feeding and nutrition are frequently reported becoming as a problem after they got discharged from hospital (26). In interventions carried out at home, health workers provided examples and evaluated feeding either through direct breastfeeding or using tools such as cups and bottles.

One of the efforts to reduce the incidence of infection is the basic care of premature babies. During home visits, the officer provided care for premature babies which were controlling vital signs, bathing the baby together with the mother, skin care, diaper rash treatment and changing diapers $(23,27)$.

Health workers also carried out care for premature babies with the aim of stabilizing their body temperature by checking the baby's body temperature and practicing KMC during home visits with mother and family $(12,28)$. KMC is useful for attaching emotion between mothers and premature babies and also maintaining the baby's body temperature to normal (the same as the mother's body temperature) because the mother can transfer her body temperature to the baby. Checking the safe and comfortable home environment also carried out by health workers by checking the room temperature of the baby's room, the room should not be too cold or hot, so that the baby's body temperature can be stable (23). Room temperature conditions are very important when it comes to caring for premature babies at home. Preparation of assistive devices to check the health condition of premature babies, for example to check the baby's body temperature using a thermometer must be available and easy to find.

\section{CONCLUSION}

The birth of premature babies has an impact on both mothers and premature babies. It needs preparation for the mother to provide optimal care for babies. Quality care is essential for the health, growth and development of premature babies and the health of the mother. Interventions need to be carried out by health workers to ensure the readiness and ability of mothers to care for their babies. Readiness and ability of mothers can be improved by providing health education in the form of increased knowledge and skills about the concept of premature baby care at home. Counseling is carried out to increase the confidence of mothers to care premature babies and to 
solve problems that is happening during the care of premature babies. Next is the provision of support from partners, family, friends and health workers who are able to improve care for premature babies. And the last one is the care for premature babies which is carried out by health workers during home visits to increase the knowledge, skills of mothers and the health of premature babies.

\section{REFERENCES}

1. WHO. Preterm birth [Internet]. WHO Publication. 2018 [cited 2021 Mar 27]. Available from: https://www.who.int/news-room/fact-sheets/detail/preterm-birth

2. WHO. Care of the preterm and low-birth-weight newborn World Prematurity Day - 17 November 2018 [Internet]. WHO Publication. 2018 [cited 2021 Mar 27]. Available from: https://www.who.int/maternal_child_adolescent/newborns/prematurity/en/

3. Julianti E, Rustina Y, Efendi D. PROGRAM PERENCANAAN PULANG DAPAT MENINGKATKAN Pendahuluan Bayi prematur berisiko tinggi mengalami ma- dan berkesinambungan dapat memberikan in- sebuah RS di Jakarta disampaikan bahwa eduMetode Penelitian ini menerapkan desain penelitian quasi experiment. 2019;22(August 2017):74-81.

4. Huff K, Rose RS, Engle WA. La te Pre ter m I n f an t s Recommendations Late preterm Morbidity Mortality Monitoring Management. Pediatr Clin NA [Internet]. 2018; Available from: https://doi.org/10.1016/j.pcl.2018.12.008

5. Rustina Y, Budi I, Tutik R, Hariyati S. How to prepare your preterm baby before discharge. 2020;49(4):390-5.

6. Veronez M, Borghesan NAB, Corrêa DAM, Higarashi IH. Experience of mothers of premature babies from birth to discharge: notes of field journals. Rev Gauch Enferm. 2017;38(2):e60911.

7. González MPO, Espitia EC. Caring for a premature child at home: From fear and doubt to trust. Texto e Context Enferm. 2014;23(4):828-35.

8. Samani E, Ahmadi A, Sharifi H. Effectiveness of cognitive-behavioral counseling on the mental health of premature infants' mothers in neonatal intensive care unit. J Neonatal Nurs [Internet]. 2020;(January):1-5. Available from:

https://doi.org/10.1016/j.jnn.2020.01.001

9. Tambunan ES, Pratomo H, Hadi EN, Rustina Y. Knowledge of low birth weight care as a source of coping strategies for mothers: Cross sectional study in perinatology WARD'S. J Neonatal Nurs [Internet]. 2020;26(5):268-72. Available from:

https://doi.org/10.1016/j.jnn.2020.01.003

10. Irving P, Long A. Counselling in Health Promotion: A Nursing Perspective. J Inst Heal Educ. 1993;31(4):126-32.

11. Schuler C, Edward G, Agbozo F. Mothers ' Experiences with Neonatal Care for Low Birth Weight Infants at Home ; A Qualitative Study in the Hohoe Municipality, Ghana. J Pediatr Nurs [Internet]. 2019;45:e44-52. Available from:

https://doi.org/10.1016/j.pedn.2018.12.017

12. Taneja S, Sinha B, Upadhyay RP, Mazumder S, Sommerfelt H, Martines J, et al. Community initiated kangaroo mother care and early child development in low birth weight infants in India-a randomized controlled trial. BMC Pediatr. 2020;20(1):1-12.

13. Jang EH, Ju HO. Effects of an infant care education program for mothers of late-preterm infants on parenting confidence, breastfeeding rates, and infants' growth and readmission 
rates. Child Heal Nurs Res. 2020;26(1):11-22.

14. Jang GJ. Influence of a breastfeeding coaching program on the breastfeeding rates and neonatal morbidity in late preterm infants. Child Heal Nurs Res. 2020;26(3):376-84.

15. Mazumder S, Taneja S, Dube B, Bhatia K, Ghosh R, Shekhar M, et al. Effect of community-initiated kangaroo mother care on survival of infants with low birthweight: a randomised controlled trial. Lancet [Internet]. 2019 Nov 9;394(10210):1724-36. Available from: https://www.proquest.com/docview/2312771077?accountid=46437

16. Evans T, Boyd RN, Colditz P, Sanders M, Whittingham K. Mother-Very Preterm Infant Relationship Quality: RCT of Baby Triple P. J Child Fam Stud [Internet]. 2017 Jan;26(1):284-95. Available from: https://www.proquest.com/docview/1856098307?accountid=46437

17. La DX, Hunter XML, Stephanie DX, Catherine DX, Anne DX. Implementing a Parent Education Program in the Special Care Nursery. J Pediatr Heal Care [Internet]. 2018;(2013):1-7. Available from: https://doi.org/10.1016/j.pedhc.2018.06.007

18. Colditz PB, Boyd RN, Winter L, Pritchard M, Gray PH, Whittingham K, et al. A Randomized Trial of Baby Triple P for Preterm Infants: Child Outcomes at 2 Years of Corrected Age. J Pediatr [Internet]. 2019;210:48-54.e2. Available from: https://doi.org/10.1016/j.jpeds.2019.01.024

19. Bazargan-Hejazi S, Ahmadi A, Shirazi A, Ainy E, Djalalinia S, Fereshtehnejad S-M, et al. The Burden of Road Traffic Injuries in Iran and 15 Surrounding Countries: 1990-2016. Arch Iran Med. 2018 Dec;21(12):556-65.

20. Hägi-Pedersen MB, Dessau RB, Norlyk A, Stanchev H, Kronborg H. Comparison of video and in-hospital consultations during early in-home care for premature infants and their families: A randomised trial. J Telemed Telecare. 2020;

21. Mazumder S, Taneja S, Dube B, Bhatia K, Ghosh R, Shekhar M, et al. Effect of community-initiated kangaroo mother care on survival of infants with low birthweight: a randomised controlled trial. Lancet [Internet]. 2019;394(10210):1724-36. Available from: http://dx.doi.org/10.1016/S0140-6736(19)32223-8

22. Kort-butler LA. Social Support Theory. 2017;(1994).

23. Namnabati M, Keyvanfar S, Sadeghnia AR. The effect of the presence of a support nurse on the safe transition of premature infants from the neonatal intensive care unit to home. $\mathrm{J}$ Babol Univ Med Sci. 2020;22(1):150-5.

24. Gutiérrez SSR, García PE, Prellezo AS, Paulí LR, Del Castillo BL, Sánchez RB. Emotional support for parents with premature children admitted to a neonatal intensive care unit: A qualitative phenomenological study. Turk J Pediatr. 2020;62(3):436-49.

25. Summergrad P. Medical psychiatry units and the roles of the inpatient psychiatric service in the general hospital. Gen Hosp Psychiatry. 1994;16(1):20-31.

26. Green J, Fowler C, Petty J, Whiting L. The transition home of extremely premature babies: An integrative review. J Neonatal Nurs [Internet]. 2021;27(1):26-32. Available from: https://doi.org/10.1016/j.jnn.2020.09.011

27. Bora Güneş N, Çavuşoğlu H. Effects of a home follow-up program in Turkey for urban mothers of premature babies. Public Health Nurs. 2020;37(1):56-64.

28. Ghazi M, Zare M, Ramezani M, Heidarzadeh M, Vashani HB. The effect of home visit program based on the continued kangaroo mother care on maternal resiliency and development of premature infant: A randomized clinical trial. Int J Community Based Nurs Midwifery. 2021;9(1):64-75. 